\title{
Multi Drug Resistant Acinetobacter Ventilator Associated Pneumonia in a Tertiary Care Hospital
}

\author{
P. Nanthini Devi ${ }^{1^{*}}$ and S. Gomathi ${ }^{2}$ \\ ${ }^{1}$ Department of Microbiology, Sree Balaji Medical College and Hospital, \\ Chennai, Tamil Nadu, India \\ ${ }^{2}$ Department of Microbiology, SRM Medical College Hospital and Research Centre, \\ Chennai, Tamil Nadu, India \\ *Corresponding author
}

\section{A B S T R A C T}

\begin{tabular}{|l|}
\hline K e y w o r d s \\
Ventilator associated \\
pneumonia, \\
Acinetobacter baumannii, \\
$\begin{array}{l}\text { Multi drug resistance, } \\
\text { Biofilm production }\end{array}$ \\
\hline Article Info \\
\hline Accepted: \\
12 March 2018 \\
Available Online: \\
10 April 2018 \\
\hline
\end{tabular}

\section{Introduction}

Ventilator associated pneumonia is defined as pneumonia that occurs after 48 hours of mechanical ventilation. The prevalence varies from 9 to 24\% (Morehead and Pinto, 2000). Pneumonia is the most common infection in the Intensive care unit and affects about $27 \%$ of critically ill patients. About $86 \%$ of them occur in intubated patients and are termed ventilator associated pneumonia. The mortality due to VAP is $50 \%$ and can reach upto $76 \%$ when VAP is caused by multidrug resistant pathogens (Richards et al., 1999; Chastre and Fagon, 2002). It leads to increased duration of mechanical ventilation, increased duration of stay in the intensive care unit and the hospital and also increased health care costs (Amin, 2009).

Early onset VAP (VAP onset $<4$ days) is usually caused by Methicillin sensitive Staphylococcus aureus, Hemophilus influenza and Streptococcus pneumoniae while Late onset VAP is caused by Methicillin resistant Staphylococcus aureus, Multidrug resistant 
Acinetobacter, Pseudomonas and beta lactamases producing Gram negative bacteria (Gastmeier et al., 2009). Nowadays Acinetobacter is an emerging pathogen in VAP. It is aerobic, non- motile, Gram negative coccobacilli, catalase-positive, oxidasenegative bacteria. It is ubiquitous and is present in the soil, water and environmental surfaces (Hanlon, 2005). It colonises the human skin and respiratory tract. It has been implicated as an opportunistic pathogen and causes a spectrum infections ranging from wound infections, respiratory infections, urinary tract infections (Howard et al., 2012). Acinetobacter can survive on abiotic surfaces in hospitals and colonise medical devices in the ICU. It has the ability to form biofilms which are aggregates of bacteria within a matrix called extracellular polymeric substances, by attaching to devices in situ (Tomaras et al., 2003). The most troublesome part is that these organisms can gain multi drug resistance by adapting to changes in environmental pressure. It has the capacity to upregulate resistance determinants and acquire resistance to a variety of antibiotics including Carbapenems (Peleg et al., 2008).

\section{Materials and Methods}

This was a prospective study conducted in the Respiratory intensive care unit complex of a tertiary care hospital for a period of one year. A total of 100 patients on ventilator were selected.

\section{Inclusion criteria}

The cases included both males and females, age greater than 18 years who were on mechanical ventilation.

\section{Exclusion criteria}

Patients who developed pneumonia within 48 hours of admission or those who were admitted with other respiratory tract infections.

\section{Methodology}

A proforma was prepared and all the details like age, gender, diagnosis at the time of admission, date and indication for ventilation, antibiotics given, investigations done, $\mathrm{x}$-ray findings, duration of mechanical ventilation, duration of ICU and hospital stay were noted. The patient was monitored from the time admission till the discharge and the outcome was recorded.

VAP was diagnosed on clinico microbiological basis using the modified CPIS (Clinical Pulmonary infection score).VAP was classified as early onset VAP (within 48-96 hours) and late onset VAP (>96 hours) (Gastmeier et al., 2009).

The endotracheal aspirates were collected processed immediately. A Gram's stain was done and sample cultured on 5\% sheep blood agar, Mac Conkey agar, Chocolate agar and incubated at $37^{\circ} \mathrm{C}$ for colony identification. The routine biochemical tests were performed. All non-fermentative, oxidase-negative, catalase-positive non motile, Gram-negative coccobacilli were identified as Acinetobacter spp. (Constantiniu et al., 2004).

\section{Antimicrobial susceptibility testing}

The purpose of the Kirby-Bauer disk diffusion susceptibility test was done to determine the sensitivity or resistance of pathogenic bacteria to various antimicrobial drugs.

\section{Antibiotics tested}

\section{Acinetobacter}

Ceftazidime $(30 \mu \mathrm{g})$, Ceftriaxone $(30 \mu \mathrm{g})$, Cefepime $(30 \mu \mathrm{g})$, Cefoperazone Sulbactam 


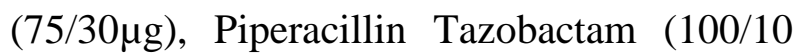
$\mu \mathrm{g})$, Amikacin $(30 \mu \mathrm{g})$, Ciprofloxacin $(5 \mu \mathrm{g})$, Cotrimoxazole $(1.25 / 23.75 \mu \mathrm{g})$, Imipenem $(10$ $\mu \mathrm{g})$, Meropenem $(10 \mu \mathrm{g})$, Tigecycline $(15 \mu \mathrm{g})$, Colistin $(10 \mu \mathrm{g})$ (Clinical and Laboratory Standards Institute, 2013).

\section{Biofilm production (Rewatkar and Wadher, 2013; Mathur et al., 2006)}

Biofilms are multicellular communities of microorganisms attached to a surface. Both Gram positive and Gram negative bacteria have the capacity to produce biofilm.

The microtitre plate was employed to estimate the biofilm production quantitatively (Morehead and Pinto, 2000).

\section{Microtitre plate method}

Colonies of the isolated bacteria causing VAP were inoculated in Trypticase soy broth (TSB) and incubated at $37^{\circ} \mathrm{C}$ for 24 hours. The culture was diluted 1:100 with trypticase soy broth. A 96 well microtitre plate with flat bottom was taken and filled with $230 \mu \mathrm{l}$ of TSB. First three wells were filled with broth only to check for sterility and non- specific binding. Known positive and negative controls were inoculated in each plate.

Then $20 \mu 1$ of the diluted cultures were added to the wells in triplicate and incubated at $37^{\circ}$ $\mathrm{C}$ for 24 hours. After incubation the plates were washed with phosphate buffer saline PBS (pH-7.2). $300 \mu \mathrm{l}$ of methanol was then added to each well and after 15 minutes, it was discarded and stained using $0.1 \%$ safranin dye.

After 20 minutes, the stain was discarded and washed with PBS. The adherent cells were resolubilised with $33 \%$ glacial acetic acid.

Optical densities (OD) of the stained adherent bacteria were measured with an ELISA reader at a wavelength of $490 \mathrm{~nm}$. The averages of the three OD values were taken. The cut off value of $\mathrm{OD}(\mathrm{ODc})$ was calculated.

\section{Minimum inhibitory concentration (Andrews, 2001)}

MICs are used in laboratories to confirm antimicrobial resistance. Microbroth dilution was performed with Meropenem powder for all Acinetobacter isolated from VAP cases. Escherichia coli ATCC 25922 was used as the Quality control.

\section{Preparation of stock solution}

Stock solutions were prepared using the formula:

1000/P x V x C = W

Where $\mathrm{P}=$ potency given by the manufacturer $(\mu \mathrm{g} / \mathrm{mg}), \mathrm{V}=$ volume required $(\mathrm{mL}), \mathrm{C}=$ final concentration of solution $(\mathrm{mg} / \mathrm{L})$ and $\mathrm{W}=$ weight of antibiotic in $\mathrm{mg}$ to be dissolved in volume $\mathrm{V}(\mathrm{mL})$.

\section{Procedure}

The organisms suspensions were prepared by inoculation into brain heart infusion broth. Prepare inoculum equivalent to a 0.5 Mcfarland standard. A final inoculum of $5 \mathrm{x}$ $10^{5} \mathrm{CFU} / \mathrm{mL}$ is required and therefore suspensions should be diluted 1:100 in broth medium.

A 96 well microtitre plate was labeled with the appropriate antibiotic dilutions.75 $\mu \mathrm{l}$ of each antibiotic dilution was added to all the rows of wells. $75 \mu$ l of ATCC E. coli 25922 was added to the first row followed by the isolates to be tested in the subsequent rows.

Inoculated and uninoculated wells of antibiotic-free broth were included. The first 
control was to check the adequacy of the broth to support the growth of the organism; the second was for check of sterility. The plates were covered with lid and incubated at 35$37^{\circ} \mathrm{C}$ for $18-20$ hours. MIC endpoint is the lowest concentration of antibiotic, at which there is no visible growth of the bacteria.

The MIC breakpoints for Meropenem against Acinetobacter $: 4$ - susceptible, 8 - intermediate and 16 - resistant (Clinical and Laboratory Standards Institute, 2013).

\section{Results and Discussion}

The total number of patients selected for the study was 100 , out of which $68 \%$ were males and $32 \%$ were females.

The highest incidence was seen in the age group of 41-60 years (44\%) followed by 61-80 years $(38 \%), 21-40$ years $(12 \%)$ and $81-100$ years $(6 \%)$.

The incidence of Acinetobacter causing Ventilator associated pneumonia was found to be $31 \%$.

Among the 31 patients with Acinetobacter VAP, $74.19 \%$ were males and $25.81 \%$ were females.

The highest incidence was recorded in the 6180 years age group (41.94\%) followed by 4160 years age group (35.48\%), 21-40 years (12.91) and 81-100 years (9.68\%). Acinetobacter baumannii was the causative agent in early onset VAP in $32.26 \%$ of cases and in late onset VAP in $67.74 \%$ of cases.

The maximum incidence was found in patients diagnosed with multisystem involvement $(38.71 \%)$, Central nervous system disorders (35.48\%), Kidney disorders (16.13\%), Cardiovascular disorders (3.23\%) and Others (poisoning, carcinoma, road traffic accidents) in $6.45 \%$ of cases. Diabetes was associated with Acinetobacter VAP in $16.13 \%$ of cases, Hypertension in $29.03 \%$, both diabetes and hypertension in $29.03 \%$ and no comorbidities in $25.81 \%$ of cases.

Acinetobacter baumannii was isolated as a single organism in $16.13 \%$ of early onset VAP and $35.48 \%$ of late onset VAP. It was isolated with other organisms, Escherichia coli, Pseudomonas aeruginosa, Klebsiella pneumoniae and Staphylococcus aureus in $16.13 \%$ of early onset VAP and $32.26 \%$ of late onset VAP.

In the case of early onset VAP, maximum resistance was observed to Amikacin, Cotrimoxazole and Ciprofloxacin followed by Ceftazidime, Ceftriazone. Among Carbapenems, 50\% resistance to Imipenem and $60 \%$ to Meropenem were noted. All the isolates were sensitive to Colistin.

In late onset VAP, maximum resistance was noted among Cotrimoxazole, Amikacin and Ciprofloxacin. Imipenem resistance was noted in $61.9 \%$ of isolates and Meropenem resistance in $57.14 \%$. None of the isolates were resistant to Colistin.

The biofilm estimation by microtitre plate method showed $54.84 \%$ of isolates to be strongly adherent, $32.26 \%$ of isolates to be moderately adherent, $6.45 \%$ to be weakly adherent and $6.45 \%$ of isolates were non adherent.

Minimum inhibitory concentration determination by micro broth dilution method showed that 12 isolates $(38.71 \%)$ were sensitive and 19 isolates (61.29\%) were resistant. Compared to disk diffusion method, MIC testing identified one more resistant isolate. Ventilator associated pneumonia is the most important nosocomial infection in the Intensive care unit. It leads to increased 
mortality and associated with increased duration of mechanical ventilation and hospital stay (Chaari et al., 2013).

Acinetobacter baumannii is a significant cause of nosocomial pneumonia especially in intubated patients. Its capacity to survive adverse environmental conditions and upregulate resistance determinants has made it a successful pathogen in hospitals (CisnerosHerreros et al., 2005).

The present study was done at a tertiary care hospital to know the incidence, characteristics and antibiotic sensitivity pattern of Acinetobacter baumannii involved ventilator associated pneumonia.

The total number of patients selected for the study was 100 after applying the inclusion and exclusion criteria, out of which $68 \%$ were males and $32 \%$ were females.

The highest incidence was seen in the age group of 41-60 years (44\%) followed by 61-80 years $(38 \%), 21-40$ years $(12 \%)$ and $81-100$ years $(6 \%)$.

\section{Incidence of VAP}

The incidence of Acinetobacter causing Ventilator associated pneumonia was found to be $31 \%$.

The present study was on par with similar studies by Ebrahimi et al., and Japoni et al., but a study by Bagheri Nesami et al., showed a higher incidence of $57.83 \%$

\section{Gender distribution of Acinetobacter VAP cases}

Among the 31 patients with Acinetobacter VAP, $74.19 \%$ were males and $25.81 \%$ were females.
In similar studies, higher incidence was noted in males which were comparable to our study.

\section{Age distribution of Acinetobacter VAP cases}

The highest incidence was recorded in the 6180 years age group (41.94\%) followed by $41-$ 60 years age group (35.48\%), 21-40 years (12.91) and 81-100 years $(9.68 \%)$.

Baraibar et al., in their study observed $12.5 \%$ of VAP cases above 60 years. The mean age was $47.8 \pm 21.7$ years for Acinetobacter VAP group according to a study by Di Bonita et al., The mean \pm SD age of these patients was 59.18: $\pm: 18.72$ years in a study by (Baraibar $e t$ al., 1997).

Hortal et al., has reported old age as a risk factor for ventilator associated pneumonia in his study.

This is because of their immunocompromised state and the mucociliary clearance efficiency is also decreased (Hortal et al., 2009).

Critically ill patients have impaired phagocytosis and behave as immunosuppressed even before the emergence of nosocomial infection.

This is due to the actions of the anaphylatoxin, C5a, which impairs neutrophil phagocytic activity (Morris et al., 2009).

Recently, a combined dysfunction of T-cells, monocytes and neutrophils has been noted to predict nosocomial infection (Morris et al., 2013).

Also Acinetobacter baumannii affects the immunocompromised and the chronically ill patients which accounts for the reason cases > 60 years were involved (Al-Anazi et al., 2012) 
Fig.1

\section{GENDER DISTRIBUTION OF STUDY GROUP}

$68 \%$

Fig.2

\section{AGE DISTRIBUTION OF THE STUDY} GROUP

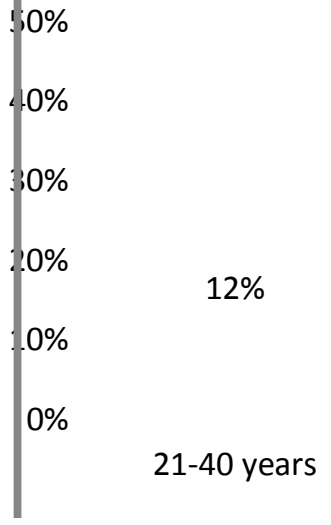

$44 \%$

$38 \%$

Age groups

$6 \%$

Fig.3

\section{INCIDENCE OF ACINETOBACTER VAP}


Fig.4

\section{GENDER DISTRIBUTION OF ACINETOBACTER VAP}

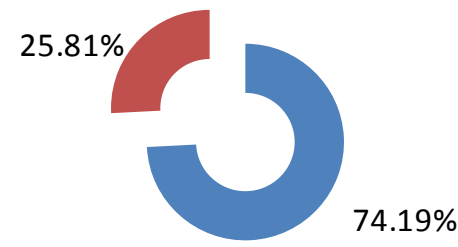

Fig.5

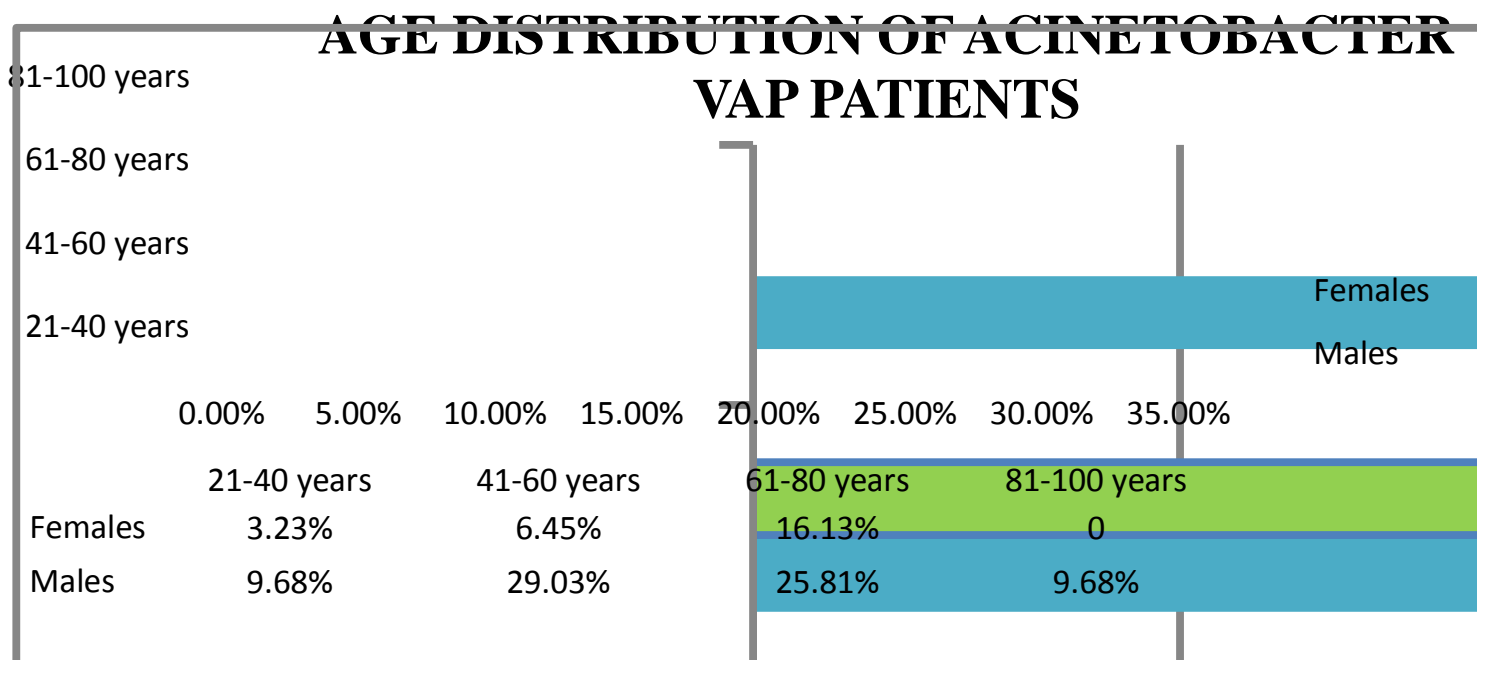

Fig.6

\section{TYPE OF VAP ASSOCIATED WITH ACINETOBACTER}

$67.74 \%$

$32.26 \%$ 
Fig.7

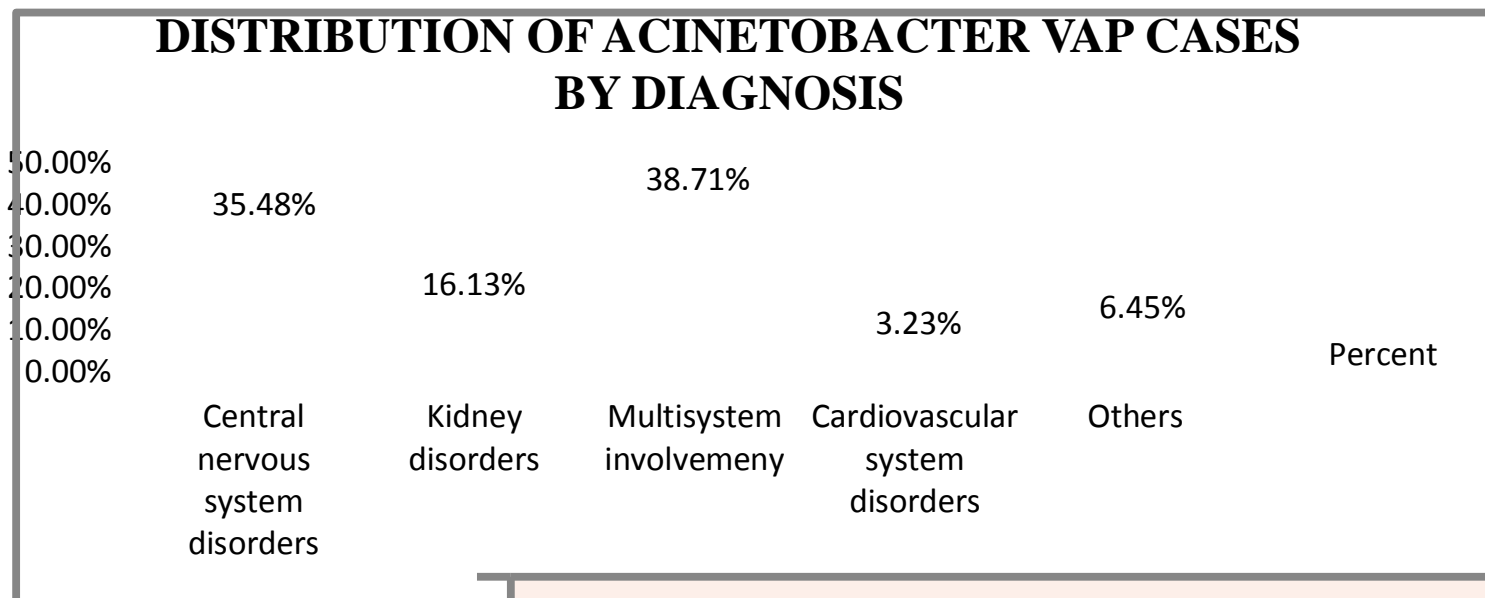

Fig.8

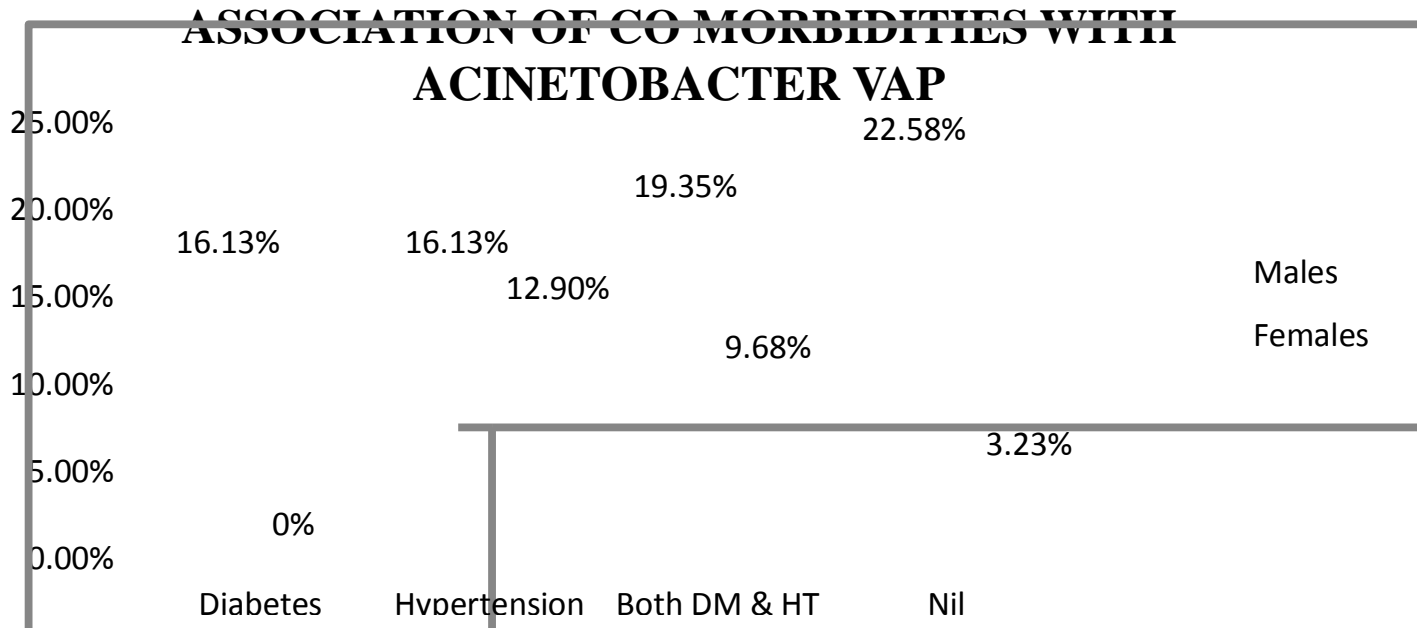

Fig.9

$60.00 \%$

RESULTS OF BIOFILM ESTIMATION

$50.00 \%$

$40.00 \%$

$32.26 \%$

$30.00 \%$

Percentage of biofilm

$20.00 \%$

$10.00 \%$

$0.00 \%$
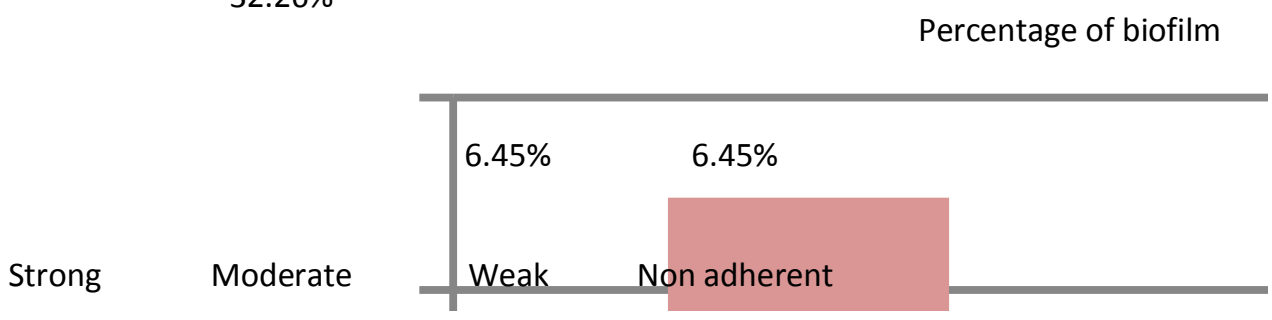
Table.1 Association of Acinetobacter VAP to microbial etiology

\begin{tabular}{|l|l|c|l|l|}
\hline \multirow{2}{*}{ Type of VAP } & \multicolumn{2}{|l|}{ Monomicrobial } & \multicolumn{2}{l|}{ Polymicrobial } \\
\hline & $\mathrm{N}$ & $\%$ & $\mathrm{~N}$ & $\%$ \\
\hline $\begin{array}{l}\text { Acinetobacter } \\
\text { early onset VAP }\end{array}$ & 5 & $16.13 \%$ & 5 & $16.13 \%$ \\
\hline $\begin{array}{l}\text { Acinetobacter } \\
\text { late onset VAP }\end{array}$ & 11 & $35.48 \%$ & 10 & $32.26 \%$ \\
\hline Total & 16 & $51.61 \%$ & 15 & $48.39 \%$ \\
\hline
\end{tabular}

Table.2 Antimicrobial resistance in Acinetobacter baumannii

\begin{tabular}{|c|c|c|c|c|}
\hline \multirow[t]{2}{*}{ Antibiotics } & \multicolumn{2}{|c|}{ Early onset VAP } & \multicolumn{2}{|c|}{ Late onset VAP } \\
\hline & $N=10$ & $\%$ & $\mathbf{N}=\mathbf{2 1}$ & $\%$ \\
\hline Ceftazidime (30 $\mu \mathrm{g})$ & 7 & $70 \%$ & 17 & $80.95 \%$ \\
\hline Ceftriaxone (30ug) & 7 & $70 \%$ & 16 & $76.19 \%$ \\
\hline Cefepime (30 $\mu \mathrm{g})$ & 6 & $60 \%$ & 14 & $71.43 \%$ \\
\hline Cefoperazone Sulbactam $(\mathbf{7 5 / 3 0} \mu \mathrm{g})$ & 5 & $50 \%$ & 16 & $76.19 \%$ \\
\hline $\begin{array}{l}\text { Piperacillin Tazobactam (100/10 } \\
\mu \mathrm{g}),\end{array}$ & 6 & $60 \%$ & 15 & $71.43 \%$ \\
\hline 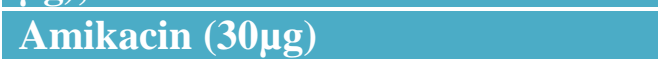 & 8 & $80 \%$ & 18 & $85.71 \%$ \\
\hline 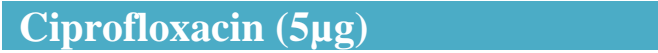 & 8 & $80 \%$ & 18 & $85.71 \%$ \\
\hline Cotrimoxazole (1.25/23.75 $\mu \mathrm{g})$ & 8 & $80 \%$ & 19 & $90.48 \%$ \\
\hline Imipenem (10 $\mu \mathrm{g})$ & 5 & $50 \%$ & 13 & $61.9 \%$ \\
\hline Meropenem $(10 \mu \mathrm{g})$ & 6 & $60 \%$ & 12 & $57.14 \%$ \\
\hline Tigecycline (15 $\mu \mathrm{g})$ & 2 & $20 \%$ & 5 & $23.81 \%$ \\
\hline Colistin (10ug) & 0 & 0 & 0 & 0 \\
\hline
\end{tabular}

Table.3 MIC Testing of meropenem by broth microdilution method

\begin{tabular}{|l|l|l|l|l|l|l|l|l|}
\hline Organisms & 0.25 & 0.5 & 1 & 2 & 4 & 8 & 16 & 32 \\
\hline $\begin{array}{l}\text { ATCC } \\
\text { Escherichia } \\
\text { coli }\end{array}$ & - & $\mathrm{S}$ & - & - & - & - & - & - \\
\hline $\begin{array}{l}\text { Acinetobacter } \\
\text { baumannii }\end{array}$ & - & - & 7 & 5 & - & - & 16 & 3 \\
\hline
\end{tabular}

Table.4 Outcomes of Acinetobacter baumannii infection in early and late onset VAP

\begin{tabular}{|l|l|l|}
\hline OUTCOME & EARLY ONSET VAP & LATE ONSET VAP \\
\hline Ventilator days & $8.1 \pm 4.43$ days & $11.62 \pm 3.69$ days \\
\hline ICU days & $9.9 \pm 5.22$ days & $12.81 \pm 3.83$ days \\
\hline Hospital days & $13.6 \pm 8.36$ days & $17.24 \pm 9.77$ days
\end{tabular}


Interpretation of biofilm production by microtitre plate method

\begin{tabular}{|c|c|}
\hline S. No \\
\hline 1. \\
\hline 2. \\
\hline 3. \\
\hline 4. \\
\hline
\end{tabular}

\begin{tabular}{|l|l|}
\hline OD Value & Biofilm \\
\hline $\mathrm{OD}<\mathrm{ODc}$ & Non-adherent \\
\hline $\mathrm{ODc}<\mathrm{OD}<2 \mathrm{ODc}$ & Weak \\
\hline $2 \mathrm{ODc}<\mathrm{OD}<4 \mathrm{ODc}$ & Moderate \\
\hline$>4 \mathrm{ODc}$ & Strong \\
\hline
\end{tabular}

Preparation of dilutions of antimicrobial agents

\begin{tabular}{|c|c|c|c|c|}
\hline Step & Concentration( & Volume & CAMHB & $\begin{array}{c}\text { Final } \\
\end{array}$ \\
\hline $\mathbf{\mu g} / \mathbf{m l})$ & $(\mathbf{m l})$ & $(\mathbf{m l})$ & concentration $(\boldsymbol{\mu g} / \mathbf{m l})$ \\
\hline $\mathbf{1}$ & 512 & 1 & 1 & 256 \\
\hline $\mathbf{3}$ & 512 & 1 & 3 & 128 \\
\hline $\mathbf{4}$ & 512 & 1 & 7 & 64 \\
\hline $\mathbf{5}$ & 64 & 1 & 1 & 32 \\
\hline $\mathbf{6}$ & 64 & 1 & 3 & 16 \\
\hline $\mathbf{7}$ & 64 & 1 & 7 & 8 \\
\hline $\mathbf{8}$ & 8 & 1 & 1 & 4 \\
\hline $\mathbf{9}$ & 8 & 1 & 3 & 2 \\
\hline $\mathbf{1 0}$ & 8 & 1 & 7 & 1 \\
\hline $\mathbf{1 1}$ & 1 & 1 & 1 & 0.5 \\
\hline $\mathbf{1 2}$ & 1 & 1 & 3 & 0.25 \\
\hline
\end{tabular}

Incidence of VAP

\begin{tabular}{|l|l|l|}
\hline Author & Incidence & Reference \\
\hline Shete et al., & $11.3 \%$ & $(17)$ \\
\hline Baraibar et al., & $8.1 \%$ & $(18)$ \\
\hline Ebrahimi et al., & $35 \%$ & $(19)$ \\
\hline Japoni et al., & $34.5 \%$ & $(20)$ \\
\hline Bagheri-Nesami et al., & $57.83 \%$ & $(21)$ \\
\hline Present study & $31 \%$ & \\
\hline
\end{tabular}

Gender Distribution of Acinetobacter VAP cases

\begin{tabular}{|l|l|l|l|}
\hline Author & Males & Females & Reference \\
\hline Tsakiridou et al., & $55 \%$ & $45 \%$ & $(22)$ \\
\hline Baraibar et al., & $66.2 \%$ & $33.8 \%$ & $(18)$ \\
\hline Castro et al., & $65.4 \%$ & $34.6 \%$ & $(23)$ \\
\hline Present study & $74.19 \%$ & $25.81 \%$ & \\
\hline
\end{tabular}




\section{Type of VAP}

Acinetobacter baumannii was the causative agent in early onset VAP in $32.26 \%$ of cases and in late onset VAP in $67.74 \%$ of cases.

Ina study by El-Saed et al., $26.5 \%$ of late onset VAP was due to Acinetobacter baumannii and early onset VAP was caused by Haemophilus spp and Streptococcus pneumoniae. But in our study, Acinetobacter baumannii was the causative agent in both types of VAP (El-Saed et al., 2013).

In another study, Acinetobacter caused early onset VAP in $25.93 \%$ of cases and late onset VAP in $74.07 \%$ of cases which is similar to our study (Sabrina et al., 2015).

\section{Diagnosis of VAP patients}

The maximum incidence was found in patients diagnosed with multisystem involvement (38.71\%), Central nervous system disorders $(35.48 \%)$, Kidney disorders (16.13\%), Cardiovascular disorders (3.23\%) and Others (poisoning, carcinoma, road traffic accidents) in $6.45 \%$ of cases.

Baraibar et al., identified cardiac arrest, ARDS, coma, heart disease, head trauma and neurosurgery as the triggers favouring Acinetobacter ventilator associated pneumonia (Baraibar et al., 1997).

In a study by Tsakiridou et al., Cardiac disorders-5\%, Neurologic disorders-18\%, Respiratory failure-41\%, Head trauma-9\%, were the underlying disorders in Acinetobacter VAP patients (Tsakiridou et al., 2014). Shete et al., identified head trauma (28.57\%), cerebral haemorrhage (14.29\%) and COPD (57.14\%) as the associated clinical conditions in Acinetobacter VAP patients (Shete et al., 2010). Ergul et al., identified chronic disorders and neurological disorders as the risk factors for the development of VAP (Ergul et al., 2017). This is because in neurological disorders there is loss of swallowing reflex and pooling of secretions which is a pre requisite for VAP (Vijai et al., 2016).

\section{Association of co-morbidities with VAP}

Diabetes was associated with Acinetobacter VAP in $16.13 \%$ of cases, Hypertension in $29.03 \%$, both diabetes and hypertension in $29.03 \%$ and no comorbidities in $25.81 \%$ of cases. In a study by Di Bonita et al., diabetes was associated with Acinetobacter VAP in $20 \%$ of cases and Hypertension in $50 \%$ of cases (Di Bonito et al., 2012). Whiles et al., found that the presence of comorbidities in any patients admitted in ICU led to increased stay in the ICU and hospital (Bristol et al., 2016).

Acinetobacter baumannii was isolated as a single organism in $16.13 \%$ of early onset VAP and $35.48 \%$ of late onset VAP. It was isolated with other organisms, Escherichia coli, Pseudomonas aeruginosa, Klebsiella pneumoniae and Staphylococcus aureus in $16.13 \%$ of early onset VAP and $32.26 \%$ of late onset VAP.

\section{Antimicrobial susceptibility of Acinetobacter baumannii isolates in early and late onset VAP}

In the case of early onset VAP, maximum resistance was observed to Amikacin, Cotrimoxazole and Ciprofloxacin followed by Ceftazidime, Ceftriazone. Among Carbapenems, $50 \%$ resistance to Imipenem and $60 \%$ to Meropenem were noted. All the isolates were sensitive to Colistin.

In a study by Shete et al., maximum resistance was observed to third generation Cephalosporins, Amikacin and Cefepime but 
all the isolates were sensitive to carbapenems (Shete et al., 2010).

In late onset VAP, maximum resistance was noted among Cotrimoxazole, Amikacin and Ciprofloxacin. Imipenem resistance was noted in $61.9 \%$ of isolates and Meropenem resistance in $57.14 \%$. None of the isolates were resistant to Colistin.

Safari et al., documented $94 \%$ resistance to Meropenem and $85 \%$ resistance to Imipenem among Acinetobacter baumannii isolated from patients in ICU wards (Safari et al., 2013).

Hasani et al., reported $100 \%$ resistance to Carbapenems and documented that Tigecycline and Colistin were the spare drugs to treat Acinetobacter VAP patients (Hasanin et al., 2016).

Multi drug resistance (MDR) is defined as resistance to at least one antimicrobial agent in three or more antimicrobial categories, extremely drug resistant (XDR), resistant to all antibiotics tested except one, Pan drug resistant (PDR), resistant to all antibiotics tested (Magiorakos et al., 2012). In the present study, 26(83.87\%) isolates were multidrug resistant. In a study by Nowak et al., 32\% (of isolates were MDR, 34\% were XDR and $31 \%$ were PDR. Fortunately in our study, none of the isolates were XDR or PDR (Nowak et al., 2017).

\section{Biofilm production by Acinetobacter isolates}

Bacterial biofilms have a role in the pathogenesis of VAP. They are aggregates of bacteria within an extrameric polymeric substance. Their determination is important because they are involved in microbial persistence and relase of VAP (Gil-Perotin et al., 2012). The biofilm estimation by microtitre plate method showed $54.84 \%$ of isolates to be strongly adherent, $32.26 \%$ of isolates to be moderately adherent, $6.45 \%$ to be weakly adherent and $6.45 \%$ of isolates were non adherent. In a study by Rao et al., $62 \%$ of Acinetobacter VAP isolates were strong biofilm producers (Rao et al., 2008). In a study by Mulla Summaiya et al., $60 \%$ of Acinetobacter VAP isolates were strong biofilm producers, $13.33 \%$ were moderate biofilm producers and $26.67 \%$ were weak biofilm producers (Summaiya and Urmi, 2012).

\section{MIC testing of Acinetobacter isolates}

Antimicrobial susceptibility testing is done in the laboratory for detection of anti -microbial resistance and to select the optimum antibiotic for treatment.

It can be done by Kirby Bauer's disk diffusion method but it is less sensitive. So Minimum inhibitory concentration testing (MIC) by microbroth dilution method was done for Meropenem which was widely used in our ICU for treatment of Acinetobacter VAP. The results showed that 12 isolates $(38.71 \%)$ were sensitive and 19 isolates (61.29\%) were resistant. Compared to disk diffusion method, MIC testing identified one more resistant isolate (Reller et al., 2009).

\section{Outcome of Acinetobacter VAP}

The ventilator days was found to be $8.1 \pm$ 4.43 days in early onset VAP and $11.62 \pm$ 3.69 days in Late onset VAP.

The length of ICU stay was found to be $9.9 \pm$ 5.22 days in early onset VAP and $12.81 \pm$ 3.83 days in Late onset VAP.

The total hospital stay was $13.6 \pm 8.36$ days in early onset VAP and 17.24 9.77 days in Late onset VAP. 
The median Ventilation days was 7(6-11) and the Length of ICU stay 15(11-34) in a study by (Hasanin et al., 2016).

The mean ICU stay was $25 \pm 17$ days in a study by (Tsakiridou et al., 2014).

\section{Mortality}

The mortality rate in case of early onset VAP caused by Acinetobacter was $30 \%$ and $38.1 \%$ in the late onset VAP. Similar studies on Acinetobacter VAP had mortality rates of $54 \%$ by (Gurjar et al., 2013) $68 \%$ by (Tsakiridou et al., 2014) and $53.3 \%$ by (Hasanin et al., 2016). Ventilator associated pneumonia is a common nosocomial infection in the ICU. It leads to increased mortality and increased health care costs. And when VAP is caused by MDR Acinetobacter, the effects are more pronounced. The prevention of VAP should be collaborative effort by the infection control team, ICU physicians and the nursing care team The preventive strategies of VAP include following the ventilator care bundles which comprises elevation of the head end of the bed, daily sedation holidays, early possible extubation, peptic ulcer and deep venous thrombosis prophylaxis.

Strict infection control measures, antibiotic stewardship programs, frequent ICU surveillance and antimicrobial resistance tracking are essential to eliminate dangerous MDR Acinetobacter infections in the ICU (Wip and Napolitano, 2009; Keyt et al., 2014).

Source of funding: None

Conflict of interest: None

\section{Acknowledgement}

The author would like to thank Dr. Radha Madhavan for her valued support and suggestions and the ICU staff team for the immense help.

\section{References}

Al-Anazi KA, Abdalhamid B, Alshibani Z, et al., Acinetobacter baumannii Septicemia in a Recipient of an Allogeneic Hematopoietic Stem Cell Transplantation. Case Reports in Transplantation. 2012; 2012: 646195. doi:10.1155/2012/646195.

Amin A. Clinical and Economic Consequences of Ventilator-Associated Pneumonia, Clinical Infectious Diseases. 2009; 49 (1): S36-S43

Andrews JM, Determination of Minimal inhibitory concentration. J Antimicrobial Chemother 2001; 48:516.

Bagheri-Nesami M, Rezai MS, Ahangarkani $\mathrm{F}$, et al., Multidrug and co-resistance patterns of non-fermenting Gramnegative bacilli involved in ventilatorassociated pneumonia carrying class 1 integron in the North of Iran. Germs. 2017; 7(3):123-131. doi:10.18683/germs.2017.1117.

Baraibar J, Correa H, Mariscal D, Gallego M, Vallés J, Rello J. Risk factors for infection by Acinetobacter baumannii in intubated patients with nosocomial pneumonia. Chest. 1997 Oct; 112(4):1050-4.

Bristol W, DeisA, Miller P, Simpson S. Comorbid Conditions Predict Outcomes in Patients with Severe Sepsis. CHEST 2016; 149 (4):A170

Castro R. Mortality rates of Acinetobacter baumannii ventilator associated pneumonia in an intensive care unit. $\mathbf{J}$ Infect Control 2015; 4 (2): 58.

Chaari A et al., Acinetobacter baumannii ventilator- associated pneumonia: epidemiology, clinical characteristics, and prognosis factors. International 
Journal of Infectious Diseases. 2013; 17(12): e1225 - e1228

Chastre J, and Fagon JY. Ventilatorassociated pneumonia, Am J Respir Crit Care Med, 2002, vol. 165 (pg. 867-903

Cisneros-Herreros JM, Garnacho-Montero J, Pachón-Ibáñez ME. Nosocomial pneumonia due to Acinetobacter baumannii. Enferm Infecc Microbiol Clin. 2005 Dec; 23 (3):46-51.

Clinical and Laboratory Standards Institute. Performance Standards for Antimicrobial Susceptibility Testing: Twenty-Third Informational Supplement M100-S23. CLSI, Wayne, PA, USA (2013).

Constantiniu S, Romaniuc A, Lancu LS, Filimon R, Taraşi I. Cultural and Biochemical Characteristics of Acinetobacter Spp. Strains Isolated From Hospital Units. The Journal of Preventive Medicine 2004; 12 (3-4): 35 42

Di Bonito M, Caiazzo S, Iannazzone M, et al., Prognostic differences between VAP from Acinetobacter baumanii and VAP from other microorganisms. Translational Medicine @ UniSa. 2012; 3:15-21.

Ebrahimi M, Khansari-nejad B, GhaznaviRad E. High frequency of ventilator associated pneumonia nosocomial coinfection caused by methicillin resistant Staphylococcus aureus and carbapenem resistant Acinetobacter baumannii in intensive care unit. J Iran Clin Res. 2015; 1:67-71.

El-Saed A, Balkhy HH, Al-Dorzi HM, Khan R, Rishu AH, Arabi YM. Acinetobacter is the most common pathogen associated with late-onset and recurrent ventilator-associated pneumonia in an adult intensive care unit in Saudi Arabia. Int J Infect Dis. 2013 Sep; 17(9): e696-701. doi: 10.1016/j.ijid. 2013. 02.004. Epub 2013 Mar 19.
Ergul AB, Cetin S, Altintop YA, et al., Evaluation of Microorganisms Causing Ventilator-Associated Pneumonia in a Pediatric Intensive Care Unit. The Eurasian Journal of Medicine. 2017; 49(2):87-91.

Gastmeier P, Sohr D, Geffers C, Rüden H, Vonberg RP and Welte T. Antimicrob. Agents Chemother. July 2009; 53 (7): 2714-2718.

Gil-Perotin S, Ramirez P, Marti V, et al., Implications of endotracheal tube biofilm in ventilator-associated pneumonia response: a state of concept. Critical Care. 2012; 16(3):R93.

Gurjar M, Saigal S, Baronia AK, et al., Carbapenem-resistant Acinetobacter ventilator-associated pneumonia: Clinical characteristics and outcome. Indian Journal of Critical Care Medicine: Peer-reviewed, Official Publication of Indian Society of Critical Care Medicine. 2013; 17(3):129-134.

Hanlon G.W. The emergence of multidrug resistant Acinetobacter species: a major concern in the hospital setting. Letters in Applied Microbiology. 2005; 41: 375-378.

Hasanin A, Mukhtar A, El-adawy A, Elazizi $\mathrm{H}$, LotfyA, Nassar H, Ghaith D. Ventilator associated pneumonia caused by extensive-drug resistant Acinetobacter species: Colistin is the remaining choice Egyptian Journal of Anaesthesia. 2016; 32: 409-413.

Hortal J, Giannella M, Pérez MJ, Barrio JM, Desco M, Bouza E, Munoz P. Incidence and risk factors for ventilator-associated pneumonia after major heart surgery. Intensive Care Med. 2009; 35(9): 151825.

Howard A, O'Donoghue M, Feeney A, Sleator RD. Acinetobacter baumannii: An emerging opportunistic pathogen. Virulence. 2012; 3(3):243-250. 
Japoni A, Vazin A, Davarpanah MA, Afkhami Ardakani M, Alborzi A, Japoni S, Rafaatpour N. Ventilatorassociated pneumonia in Iranian intensive care units. J Infect Dev Ctries. 2011 Apr 26; 5(4):286-93.

Keyt H, Faverio P, Restrepo MI. Prevention of ventilator-associated pneumonia in the intensive care unit: A review of the clinically relevant recent advancements. The Indian Journal of Medical Research. 2014; 139(6):814-821.

Magiorakos AP, Srinivasan A, Carey RB, Carmeli Y, Falagas ME, Giske CG, Harbarth S, Hindler JF, Kahlmeter G, Olsson-Liljequist B, Paterson DL, Rice LB, Stelling J, Struelens MJ, Vatopoulos A, Weber JT, Monnet DL. Multidrug-resistant, extensively drugresistant and pandrug-resistant bacteria: an international expert proposal for interim standard definitions for acquired resistance. Clin Microbiol Infect. 2012 Mar; 18(3):268-81.

Mathur T, Singhal S, Khan S, Upadhyay DJ, Fatma T, Rattan A. Detection of biofilm formation among the clinical isolates of Staphylococci: an evaluation of three different screening methods, Indian Journal of Medical Microbiology, 2006; 24 (1):25-9.

Morehead RS, and Pinto SJ. VentilatorAssociated Pneumonia. Arch Intern Med. 2000; 160(13):1926-1936. doi:10.1001/archinte.160.13.1926

Morris AC, Anderson N, Brittan M, Wilkinson TS, McAuley DF, Antonelli J, McCulloch C, Barr LC, Dhaliwal K, Jones RO, Haslett C, Hay AW, Swann DG, Laurenson IF, Davidson DJ, Rossi AG, Walsh TS, Simpson AJ. Combined dysfunctions of immune cells predict nosocomial infection in critically ill patients. Br J Anaesth. 2013; 111(5):778-87.
Morris AC, Kefala K, Wilkinson TS, Dhaliwal K, Farrell L, Walsh T, Mackenzie SJ, Reid H, Davidson DJ, Haslett C, Rossi AG, Sallenave JM, Simpson AJ. C5a mediates peripheral blood neutrophil dysfunction in critically ill patients. Am J Respir Crit Care Med. 2009; 180(1):19-28.

Nowak J, Zander E, Stefanik D Higgins PG, RocaI, Vila J, McConnell MJ, Cisneros JM, Seifert H.High incidence of pandrug-resistant Acinetobacter baumannii isolates collected from patients with ventilator-associated pneumonia in Greece, Italy and Spain as part of the Magic Bullet clinical trial. Journal of Antimicrobial Chemotherapy. 2017; 72, (12): 32773282 ,

Peleg AY, Seifert H, Paterson DL. Acinetobacter baumannii: Emergence of a Successful Pathogen. Clinical Microbiology Reviews. 2008; 21 (3):538-582.

Rao RS, Karthika RU, Singh SP, Shashikala $\mathrm{P}$, Kanungo R, Jayachandran S, et al., Correlation between biofilm production and multiple drug resistance in imipenem resistant clinical isolates of Acinetobacter baumannii. Indian Journal of Medical Microbiology 2008; 26(4):333-7

Reller LB, Weinstein M, Jorgensen JH, Ferraro MJ. Antimicrobial Susceptibility Testing: A Review of General Principles and Contemporary Practices, Clinical Infectious Diseases. 2009; 49(11): 1749-1755.

Rewatkar A R, and Wadher BJ. Staphylococcus aureus and Pseudomonas aeruginosa - Biofilm formation Methods, IOSR Journal of Pharmacy and Biological Sciences. 2013; 8(5): 36-40.

Richards MJ, Edwards JR, Culver DH, Gaynes RP. Nosocomial infections in 
medical intensive care units in the United States. National Nosocomial Infections Surveillance System. Crit Care Med. 1999 May; 27(5):887-92.

Sabrina R, Souza FAL, Miyuki SL, Gomes CTP, Amaral de CP, da Fonseca BDW et al., Spread of multidrug-resistant Acinetobacter baumannii and Pseudomonas aeruginosa clones in patients with ventilator-associated pneumonia in an adult intensive care unit at a university hospital. Braz $\mathrm{J}$ Infect Dis.2015 Aug; 19(4): 350-357.

Safari, M., M. Saidijam, A. Bahador, et al., High prevalence of multidrug resistance and metallo-beta-lactamase (M $\beta \mathrm{L})$ producing Acinetobacter baumannii isolated from patients in ICU wards, Hamadan, Iran J Res Health Sci,2013; 13 (2): 162-167.

Shete VB, Ghadage DP, Muley VA, Bhore AV. Multi-drug resistant Acinetobacter ventilator-associated pneumonia. Lung India : Official Organ of Indian Chest Society. 2010; 27(4):217-220.

Summaiya MA, and Urmi JN. Assessment of biofilm formation by the causative organisms of ventilator associated pneumonia at intensive care unit of a tertiary care hospital. Natl J Med Res. 2012; 2(1): 15-18.

Tomaras AP, Dorsey CW, Edelmann RE, Actis LA. Attachment to and biofilm formation on abiotic surfaces by Acinetobacter baumannii: involvement of a novel chaperone-usher pili assembly system. Microbiology. 2003 Dec; 149(Pt 12): 3473-84.

Tsakiridou E, Makris D, Daniil Z, Manoulakas E, Chatzipantazi V, Vlachos O, Xidopoulos G, Charalampidou O, Zakynthinos E. Acinetobacter baumannii Infection in Prior ICU Bed Occupants Is an Independent Risk Factor for Subsequent Cases of Ventilator-Associated Pneumonia. BioMed Research International 2014; 2014:1-7.

Vijai MN, Ravi PR, Setlur R, Vardhan H. Efficacy of intermittent sub-glottic suctioning in prevention of ventilatorassociated pneumonia- A preliminary study of 100 patients. Indian J Anaesth. 2016 May; 60(5):319-24.

Wip C, and Napolitano L. Bundles to prevent ventilator-associated pneumonia: how valuable are they? Curr Opin Infect Dis. 2009 Apr; 22(2): 159-66.

\section{How to cite this article:}

Nanthini Devi, P. and Gomathi, S. 2018. Multi Drug Resistant Acinetobacter Ventilator Associated Pneumonia in a Tertiary Care Hospital. Int.J.Curr.Microbiol.App.Sci. 7(04): 14481463. doi: https://doi.org/10.20546/ijcmas.2018.704.164 